\title{
Passive Long-Distance Migration of Apterous Dryinid Wasps Parasitizing Rice Planthoppers
}

\author{
Toshiharu Mita1, Yukiko Matsumoto2, \\ Sachiyo Sanada-Morimura ${ }^{3}$ and Masaya Matsumura ${ }^{3}$ \\ ${ }^{1}$ Laboratory of Entomology, Faculty of Agriculture, \\ Tokyo University of Agriculture, Atsugi, \\ ${ }^{2}$ National Institute of Agrobiological Sciences, Owashi, Tsukuba, \\ ${ }^{3}$ National Agricultural Research Center for Kyushu Okinawa Region, Koshi, \\ Japan
}

\section{Introduction}

The wasp family Dryinidae comprises predator and parasitoid wasps of leaf- and planthoppers (Hemiptera: Auchenorrhyncha). This family is morphologically distinct from other wasps. Females in most subfamilies of Dryinidae have forelegs that are modified into a chela, with an enlarged claw (Fig. 1: green) and 5th tarsomere (Fig. 1: red) that aid in grasping the host insect. The enlarged claw moves widely when the chela opens. Such foreleg morphology is not always the case, such as for females of the subfamily Aphelopinae R.C.L. Perkins and Erwiniinae Olmi \& Guglielmino (Olmi \& Guglielmino, 2010) that have simple forelegs. Dryinid wasps often show distinctive sexual dimorphism, such as the presence or absence of chela. The subfamily Gonatopodinae Kieffer is one of the extreme cases of sexual dimorphism, but in this case it is because females of most of the species are apterous. The pterothorax becomes so slender in the apterous form (Fig. 2: A, C) that they look like ants. In contrast, males have well developed wings and a pterothorax (Fig. 1: B).

Since apterous females cannot disperse very far by themselves, the current distribution of these wasps should have been caused by historical events, such as terrestrial immigration and local extinction. Immigration over large distances, especially across geographical barriers (e.g. open water) seems unlikely. Recent studies revealed the annual long-distance migration of rice planthoppers, which are host to apterous dryinids. If rice planthoppers carry dryinid larvae to distant locations, immigrant individuals of the Dryinidae should be recognizable from the destination locality. This behavior can be viewed as passive longdistance migration. Confirming the presence or absence of such behavior and determining the degree of influence that this has on a population at the destination locality will broaden our understanding on the current biogeographical distribution of the Dryinidae. In this chapter, we introduce a brief summary about apterous species of Haplogonatopous R.C.L. Perkins, which are common in Asian rice paddies. We then describe the life cycle of one of these species that inhabits other vegetation, discuss the possible mechanism for settling in a new environment, and show an important insight indicated from our recent phylogeographical approach using two species of Haplogonatopus. 


\section{Common species of Haplogonatopus in Asian rice paddies}

This section briefly summarizes previous studies about Haplogonatopus species that parasitize rice planthoppers in monsoon Asia. There are two common species in rice paddies. The present understanding of the morphological differences, host ranges, and distribution of the two species are described.

\subsection{Taxonomy}

Like many other taxa of the subfamily Gonatopodinae, females of Haplogonatopus are wingless. The small palpal formula, $2 / 1$ is one of the most distinctive apomorphies of this genus. The presence of "rhinarium" on the antennae, the large subapical tooth and a single row of lamellae on the enlarged claw, and a single spur on the hind tibia are also diagnostic characters for the female (Olmi, 1984, 1999). However, the combination of those latter character states also occurs within Gonatopus Ljungh. Among the four species of Haplogonatopus distributed in the Palaearctic and Oriental regions, H. apicalis R.C.L. Perkins, 1905 and H. oratrius (Westwood, 1833) are common in Asian rice paddies. Their appearance is very similar to each other, but they are morphologically distinguishable by the female coloration and male genitalia (Fig. 2).

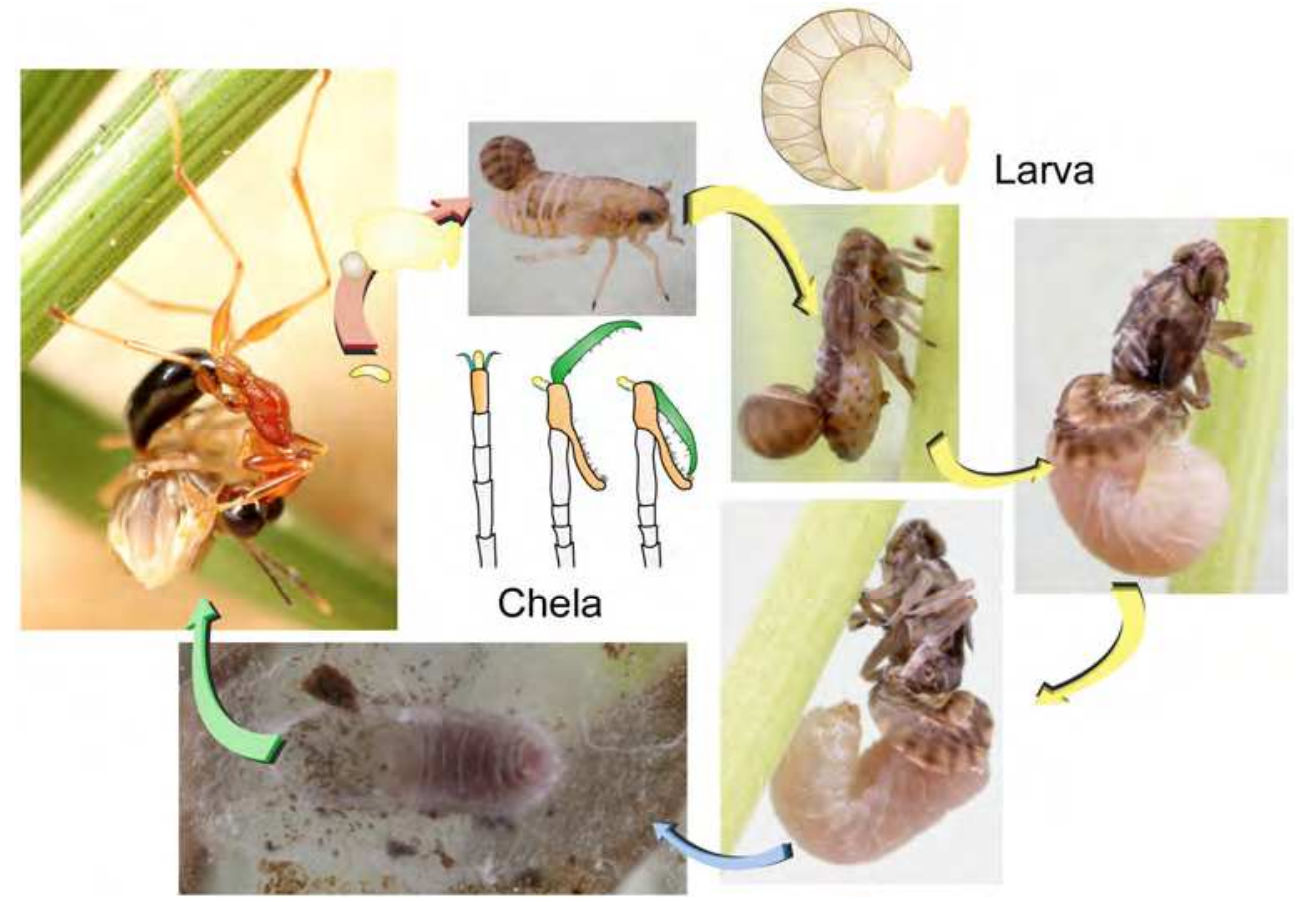

Fig. 1. Life cycle of Haplogonatopus oratrius.

\subsection{Biology}

Although the biology of most dryinid species is not well studied, species parasitizing rice planthopper are relatively well understood. H. apicalis attacks the white-backed planthopper, 
Sogatella furcifera (Horváth, 1899), and H. oratrius attacks the small brown planthopper, Laodelphax striatellus (Fallén, 1826) (Fig. 1). The host preference shows an important contrast. H. apicalis only parasitizes $S$. furcifera under natural conditions; although there are other host records (Guglielmino \& Olmi, 1997), they are apparently exceptional. H. oratrius parasitizes many species (Guglielmino \& Olmi, 1997), although the dominant host species in Asia is L. striatellus. The large biomass of L. striatellus could be advantageous for H. oratrius, as the wasp hibernates as a larva in the nymphs of this planthopper (Nishioka, 1980; Kitamura, 1987). Nishioka (1980) reported that a female $H$. apicalis was reared from an overwintering nymph of L. striatellus in Kochi Prefecture, southern Shikoku. However, despite an intensive field survey, parasitism of $H$. apicalis on L. striatellus has not been observed in Shimane, western Honshu (Kitamura, 1987, 1989; Kitamura \& Nishikata, 1987). In view of the above, the hibernation of $H$. apicalis in L. striatellus is unlikely to be common in the temperate region.

The general life cycle of Haplogonatopus can be summarized as follows (Fig. 1). An adult female captures a host using its chela ( $=$ distal apex of modified foreleg) and oviposits an egg into the posterior part of abdomen. The larva develops in the abdomen of the host. The mature larva consumes the entire content of the host, and then emerges from the host's body. The larva spins a cocoon on plant tissue.

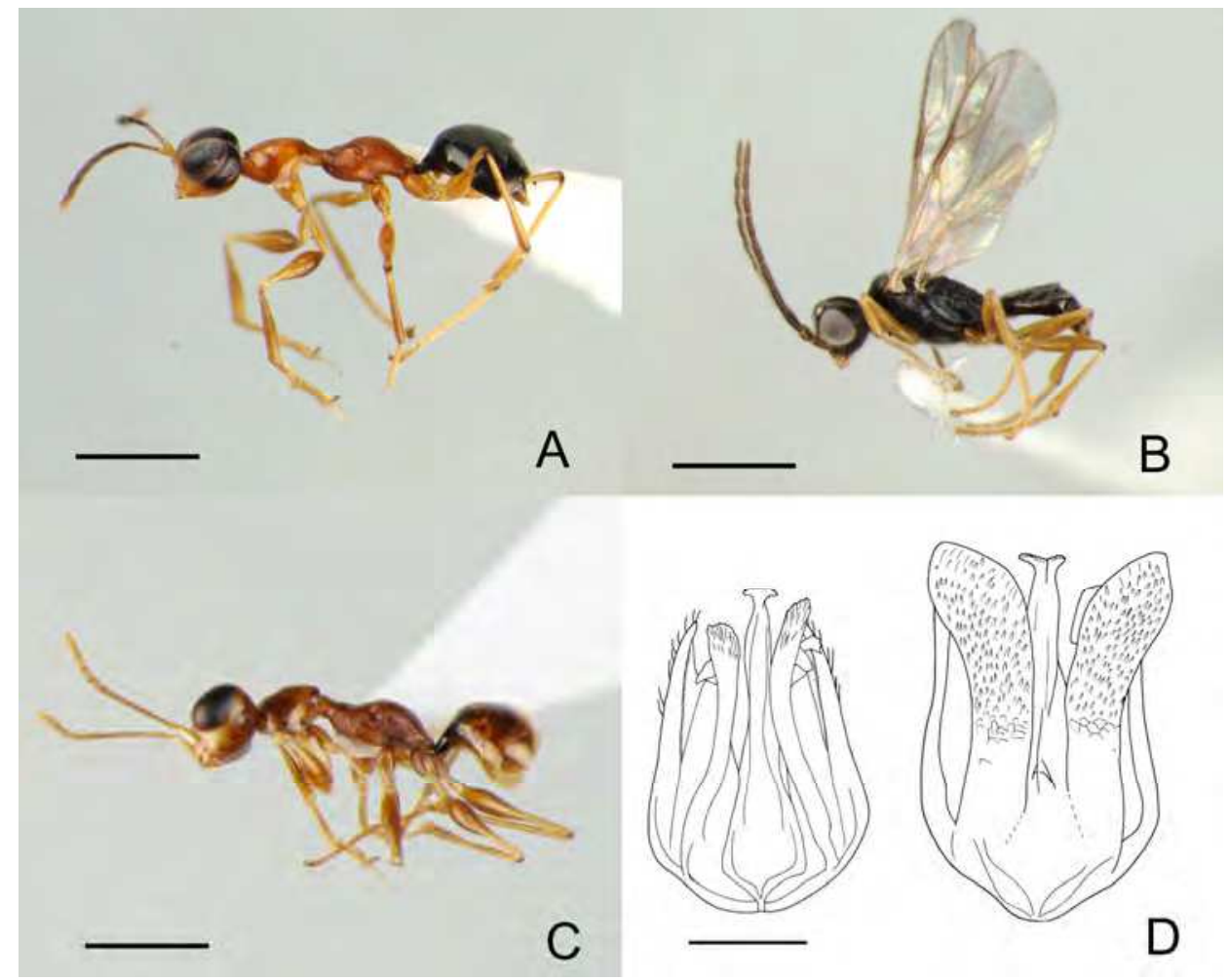

Fig. 2. General habitus and male genital organs of Haplogonatopus that are common in rice paddies. A H. oratrius, female; B ditto, male; $\mathrm{C}$ H. apicalis, female; D male genitalia, H. oratrius (left), H. apicalis (right). Scale $=1.0 \mathrm{~mm}(\mathrm{~A}-\mathrm{C}), 0.1 \mathrm{~mm}(\mathrm{D})$. 


\subsection{Distribution}

The distribution of the two Haplogonatopus species overlaps with the main distribution of their dominant hosts. H. oratrius is common from Europe to the temperate region of Asia, including Taiwan. Although there is no record from South East Asia, they have been recognized from the Mariana Islands (Olmi, 1999). Recently, they were found in the oceanic and tropical Bonin Islands (Mita, unpublished data). Many organisms have been accidentally introduced to new regions by human activity, and the distribution of $H$. oratrius needs additional evaluation. H. apicalis was originally described from Northern Australia. However, it is rather common in Monsoon Asia. There is no record from oceanic islands, but its host, $S$. furcifera, is distributed in Fiji, Micronesia and New Hebrides (Asche \& Wilson, 1990).

\section{Seasonal host shift of Haplogonatopus oratrius}

Adult L. striatellus often moves a short distance from a rice paddy, but the destination locality may not be always suitable. This section will show recent results of field research conducted on vegetation unsuitable for L. striatellus.

As it is too cold for winter rice cropping in Japan, L. striatellus needs to hibernate on other vegetation. They can be found at paddy-side levees occupied with grasses. They may also be found in dry river beds occupied by Eragrostis curvula (Schrad.) Nees in autumn. Another planthopper, Hosunka hakonensis (Matsumura, 1935) is the predominant species in the bush of E. curvula. They also successfully reproduce and thrive on E. curvula. However, $L$. striatellus do not appear to reproduce on this plant as nymphs are not found on it. Figure 3 shows the seasonal fluctuation of $H$. hakonensis collected from a colony of E. curvula at Sagami-gawa River (Kanagawa, Central Honshu) by net-sweeping. The field research was conducted four times a month from April to October on 2006. The sweeping-netting was undertaken for 20 minutes each sampling. Nymphs were collected from April to September but they were also found in winter (data not shown). Conversely, all collected individuals of L. striatellus collected from E. curvula were adults and nothing was collected from April to June (Fig. 4). H. oratrius and Gonatopus dromedarius (A. Costa, 1882) inhabit the same environment. When nymphs parasitized by Dryinidae were collected, they were kept in a plastic tube with a grass leaf until the dryinid larvae emerged. The identification of dryinid species was undertaken on adults or, when they did not become adults, by coloration of the larval sac. The two dryinid species are easily identified by the color of the larval sac: in $H$. oratrius it is ash gray (Fig. 1), whereas in G. dromedarius it is black. H. hakonensis were found to be parasitized by both dryinid species (Figs. 3, 5). The rate of parasitism was highest in June (Fig. 5), and most dryinid species parasitizing H. hakonensis in June were G. dromedarius (H. hakonensis: L. striatus $=34:$ 11). Because parasitism of overwintering nymphs by both dryinid species was observed in April, H. hakonensis is regarded as a winter host.

The seasonal fluctuation of L. striatellus at Sagami-gawa River is similar to that of a paddyside levee (Figs. 4, 6), except that the latter contains adults and nymphs (data not shown). At Sagami-gawa River, parasitism was observed in September (Fig. 5). All of the dyrinids were $H$. oratrius except for one female G. dromedarius (L. striatus: H. hakonensis = 23: 1 ). The parasitism of G. dromedarius toward L. striatellus appeared to be highly restricted. In a paddy-side levee at Atsugi, L. striatellus was not collected from April through May (Fig. 6). However, this result may have resulted from low density. Kitamura (1989) reported the presence of overwintering nymphs and a relatively high ratio of parasitism (9-34\%) by $H$. oratrius in a similar environment from winter to spring in Shimane. 


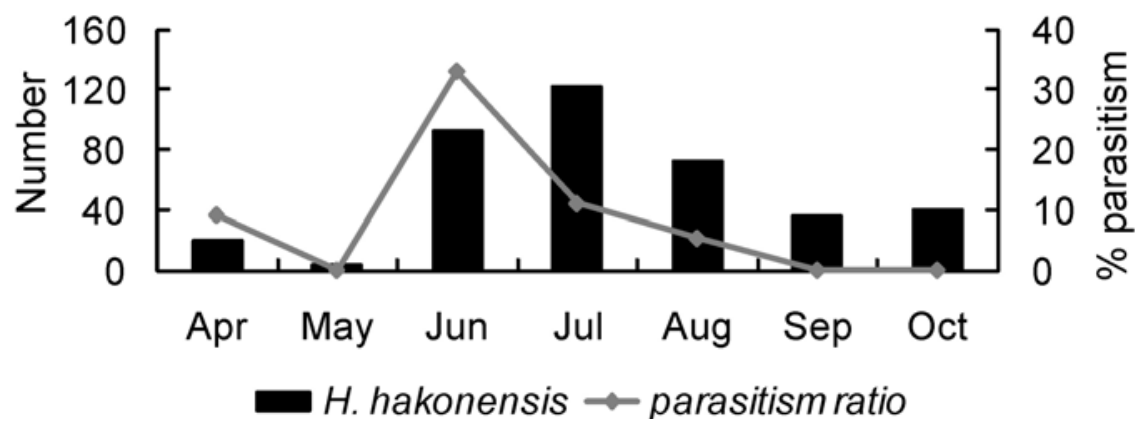

Fig. 3. Seasonal fluctuation of Hosunka hakonensis and parasitism by Dryinidae at Sagami-gawa River in 2006.

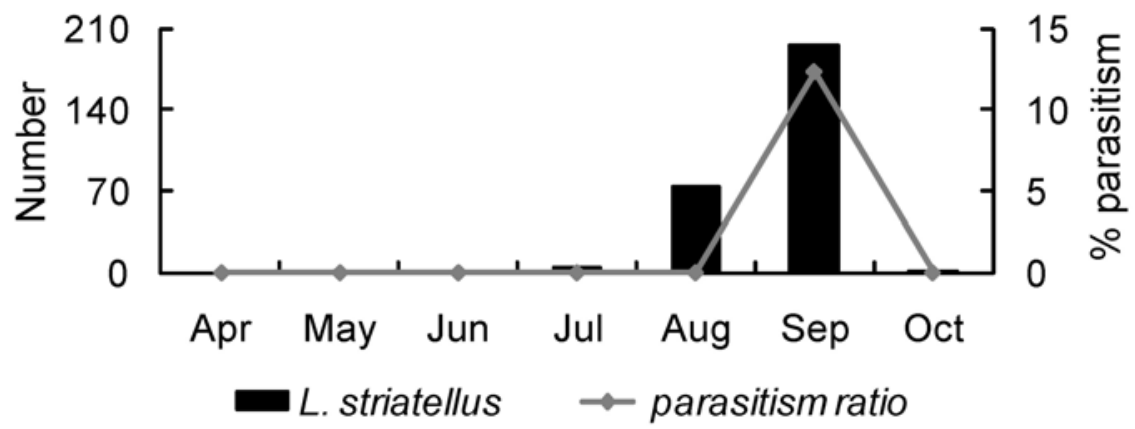

Fig. 4. Seasonal fluctuation of Laodelphax striatellus and parasitism by Haplogonatopus oratrius at Sagami-gawa River in 2006.

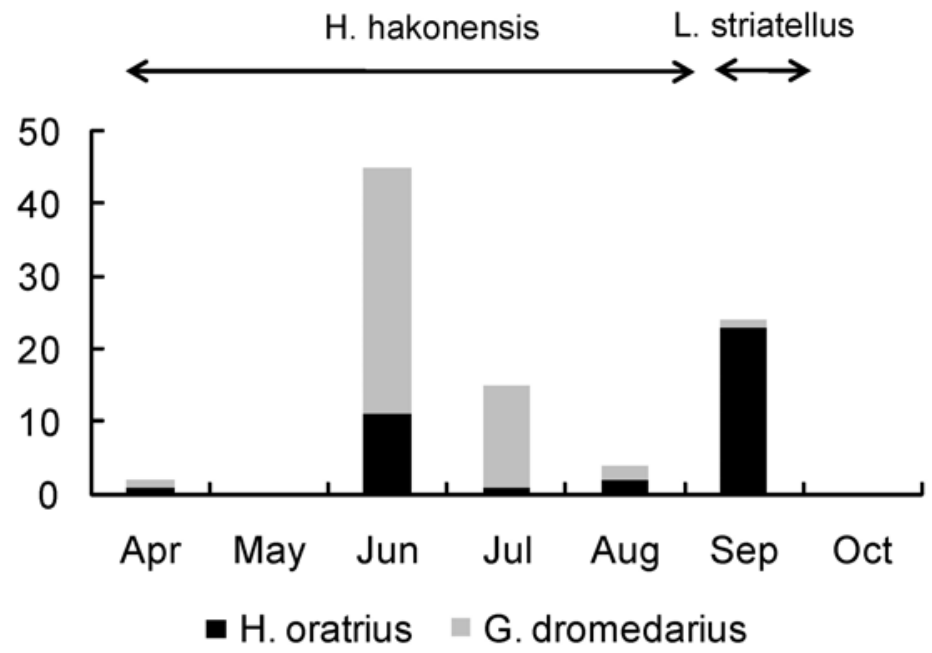

Fig. 5. Seasonal fluctuation of dryinid wasps that emerged from Hosunka hakonensis and Laodelphax striatellus at Sagami-gawa River in 2006. 
The abundance of parasitizing dryinid individuals indicates that G. dromedarius had one population peak in June in 2006. Although the host species was different from that of $G$. dromedarius, $H$. oratrius displays two population peaks, one each in June and September (Fig. 5). Kitamura's (1983) developmental model based on physiology and ambient temperature indicated that $H$. oratrius can have five generations a year in Matsue, Shimane Prefecture. As the climate in Kanagawa is similar to that of Shimane, the two observed population peaks are considered to be caused by a lack of host resource abundance (Figs. 3, 4).

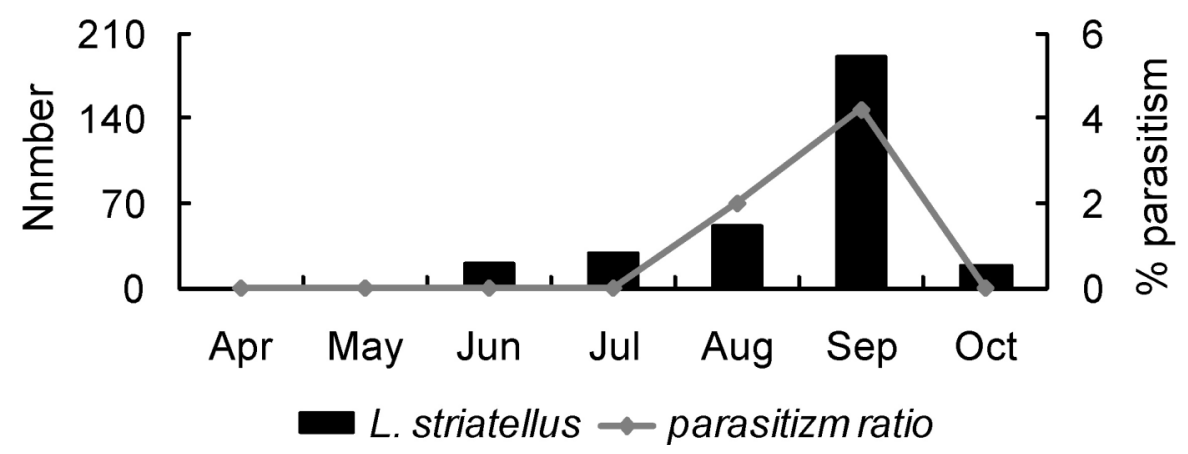

Fig. 6. Seasonal fluctuation of Laodelphax striatellus and parasitism by Haplogonatopus oratrius at a paddy-side levee in Atsugi in 2006.

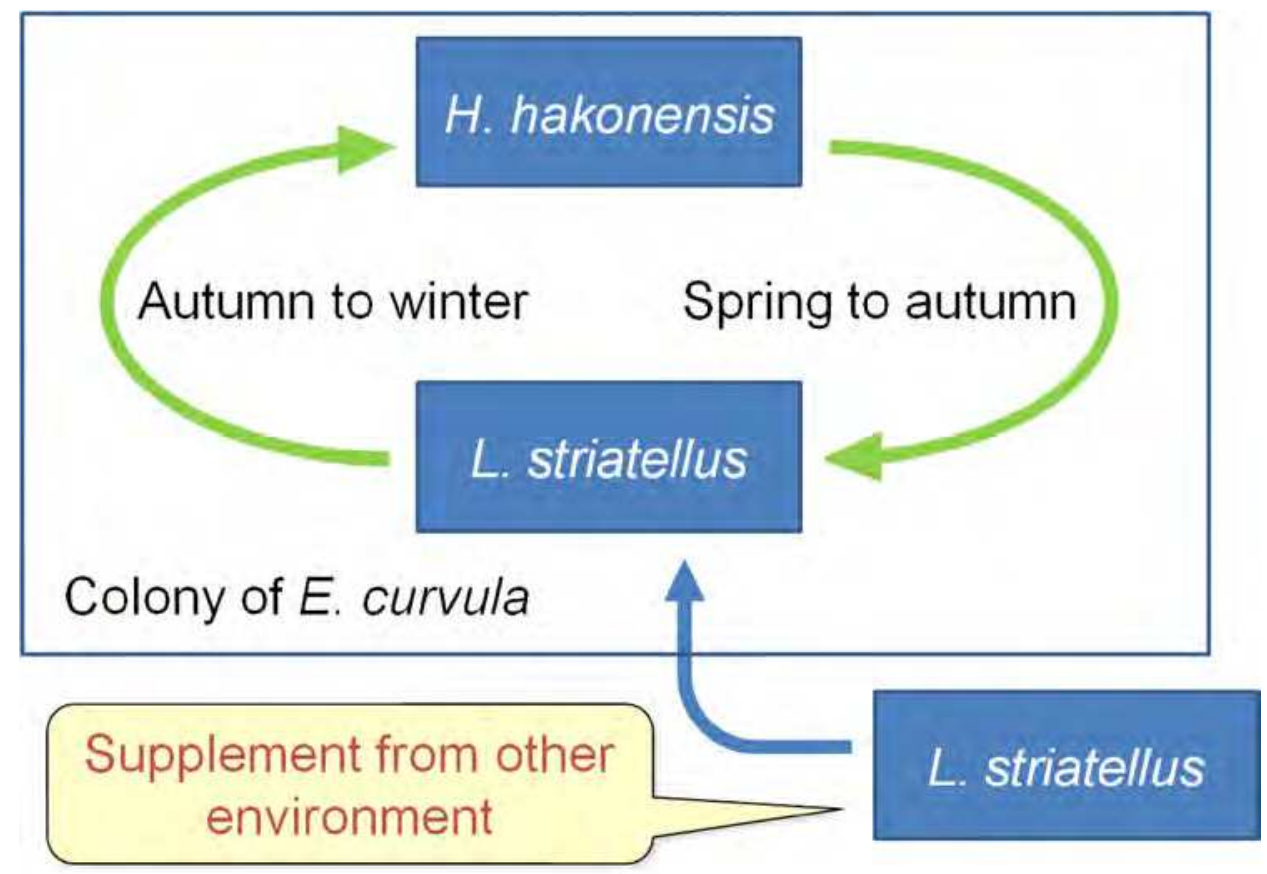

Fig. 7. Host-shift cycle of Haplogonatopus oratrius occurring on a colony of Eragrostis curvula. Hosunka hakonensis hibernates on E. curvula whereas Laodelphax striatellus dies in winter. 
Adults of immigrant L. striatellus could be already parasitized by $H$. oratrius, as indicated in Fig. 6. Therefore, $H$. oratrius both the original inhabitants and immigrants, coexist in the same locality during autumn. In winter, overwintering nymphs of $H$. hakonensis are considered to be parasitized by both species. The seasonal host shift and life cycle of $H$. oratrius at Sagami-gawa River are summarized in Fig. 7. Although H. oratrius parasitizes only L. striatellus and H. hakonensis at Sagami-gawa River, many planthopper species can be parasitized by $H$. oratrius (Guglielmino \& Olmi, 1997). We conclude that the relatively wide host range allows $H$. oratrius to settle in new environments when the parasitized hosts relocate.

\section{Long-distance migration of rice planthoppers}

S. furcifera and L. striatellus, together with the brown planthopper, Nilaparvata lugens (Stål, 1854) are the dominant planthopper pests of the rice plant in Asia. They are known as longdistance migrant insects (Kisimoto, 1975). Their migration ability in Asia has been demonstrated by temporal biotype changes (Sogawa, 1992, 1993) and migration analysis (Otuka et al., 2005a, 2005b, 2008, 2010).

S. furcifera is a tropical to subtropical species. Those found in Japan in the rainy season (June to July) originated from northern Vietnam via southern China (Sogawa, 1993; Otuka et al., 2008). As S. furcifera cannot hibernate in temperate regions, including Japan and Korea, it is thought that they immigrate from overseas each year. Conversely, L. striatellus is a temperate species. It is distributed mainly in the temperate to subarctic regions of Asia to Europe, but also in some subtropic or tropic regions (Taiwan, southern China, the high altitude areas of Southeast Asia). They hibernate as fourth instar nymphs (Kisimoto, 1957). Planthoppers captured at a weather ship on the East China Sea include many L. striatellus (Kisimoto, 1983), but this species is not distributed in the lower altitude areas of the tropic region, as are the other two planthoppers. Recently, a mass migration of L. striatellus from around Jiangsu Province of China to Kyushu, Japan, was strongly indicated by trap catches and source estimation using backward trajectory analysis (Otuka et al., 2010).

\section{Parasitized rice planthoppers collected over the ocean}

Several authors have reported that the parasitism of dryinid larval sacs and stylops on rice planthoppers was probably a direct result of migration from overseas. Kisimoto (1975) reported parasitized $S$. furcifera and $N$. lugens collected by a monitoring net trap for migrant insects. Kitamura \& Nishikata (1987) reported the seasonal changes of parasitism ratio on leaf- and planthoppers probably migrated from China. The above two observations were conducted on land. The parasitizing dryinid larvae and stylops were also recognized from individuals collected over the ocean. In 1967 and 1968, a mass flight of S. furcifera and N. lugens was observed around the weather ship, "Ojika" in the Pacific Ocean (N29 , E135 ) (Kisimoto, 1983; Kisimoto \& Sogawa, 1995). Three females of $H$. apicalis were reared from $S$. furcifera collected from the ship in 1968. These species have also been found over the East China Sea. S. furcifera parasitized by stylops and dryinids were collected on the weather ship, "Keifu-maru", on the East China Sea (N31", E126 ) in 1984 (Noda, 1986). The stylops was identified as Elenchus japonicus (Esaki \& Hashimoto, 1931) (Kifune \& Maeta, 1986). The dryinid species was not identified, but was likely $H$. apicalis. 


\section{Genetic variation among East Asian populations}

The phylogeographical analysis was conducted using the two species of Haplogonatopus based on 807-bp mitochondrial COI sequence data obtained from many localities in East Asia (Fig. 8). The monophyly of the species was strongly supported by cladistic analysis. In the parsimonious network of $H$. oratrius, a combination of three star-like core haplotype groups (Fig. 9, A-C) was indicated. The largest haplotype, group A, was composed from China, Taiwan and Kyushu elements. Haplotype group C was regarded as the Japanese endemic population. Haplotype group B was composed from mainly Japanese elements, but a few foreign elements were also included. The network structure was moderately equivalent to the geographical distribution. On the other hand, the network of H. apicalis is complicated. A single star-like structure and two circular structures were recognized. Most of the others show multimodal distribution and the structure is very different from the geographical distribution. Compared to $H$. oratrius, $H$. apicalis has high genetic variation over all localities sampled. However, they could not been isolated by geographical distribution. This could imply that all sampling sites should be regarded as the same population, which would be consistent with the annual long-distance migration of S. furcifera. However, S. furcifera showed no genetic variation among the East Asian populations sampled (Mun et al., 1999). Because the present study investigated the original and the secondary migration direction, the similar genetic structure of $H$. apicalis might be retrieved from the other localities in East

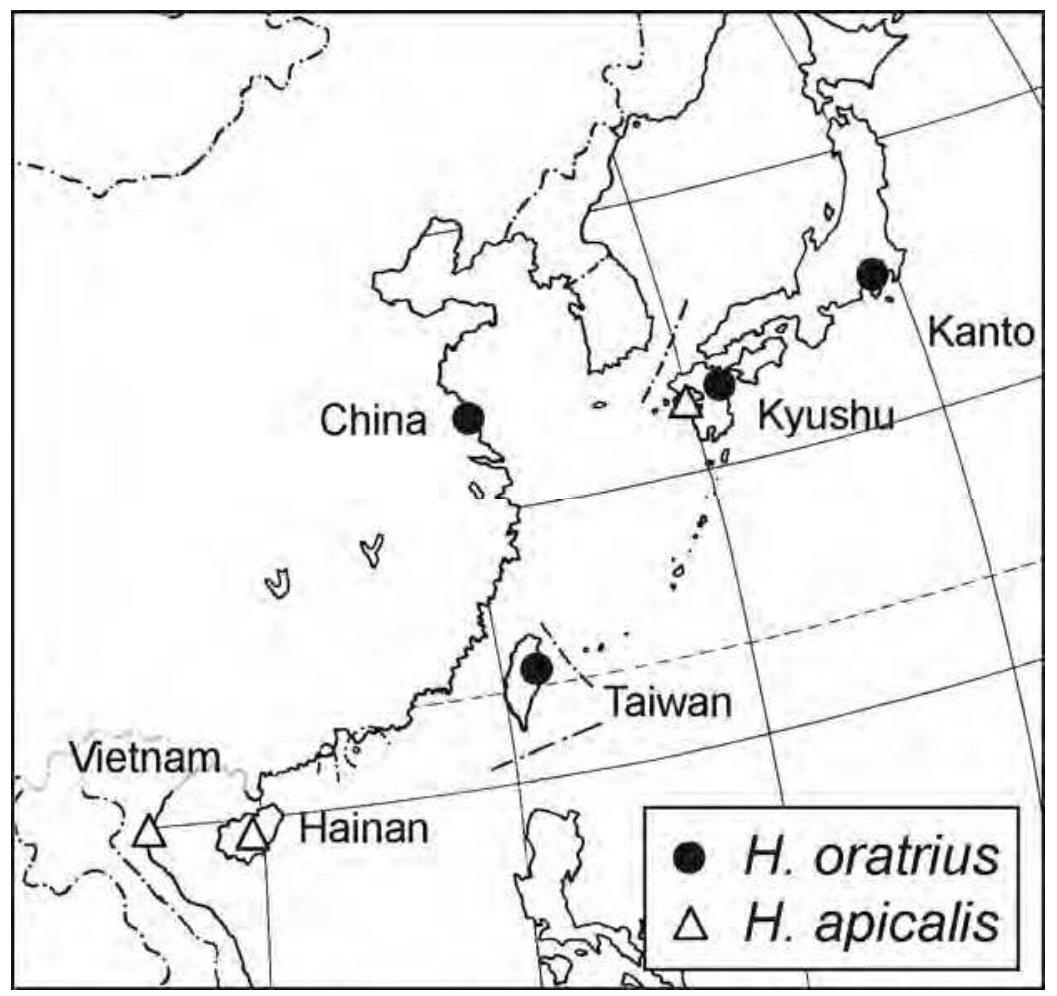

Fig. 8. Sampling localities. 
Asia. However, East Asia is only part of the distribution. The genetic structure in South East Asia and South Asia is disputed.

The haplotype network of $H$. oratrius moderately reflects geographical distances. This pattern is similar to E. japonicus (Matsumoto et al., 2011). The stylops can parasitize all three rice planthoppers and other species. Furthermore, host preference is considered to differ with region (Maeta et al., 2007; Chandra, 1980). Conversely, H. oratrius mostly relies on $L$. striatellus as a host resource, and thus the geographical difference in host preference, excluding L. striatellus, could be a minor effect. The genetic structure of the Kyushu population sampled was intermediate between the Kanto and Taiwan-China populations. Haplotypes are seemingly composed of two elements: the more-variable part directly connected with Kanto, and the less-variable part connected with Taiwan and China. The natural populations of Kyushu, Taiwan and China probably share many haplotype components. However, the dominant haplotypes among the three populations are observed in haplotype group A (Fig. 9). This indicates a current large gene flow caused by the migration of parasitized L. striatellus. The haplotype network of Taiwan and China is somewhat simpler than the Japanese populations. They are geographically distant, but genetically indistinguishable. The current migration of L. striatellus between Taiwan and China should be tested. Otherwise, it is possible that $H$. oratrius has experienced past fragmentation.
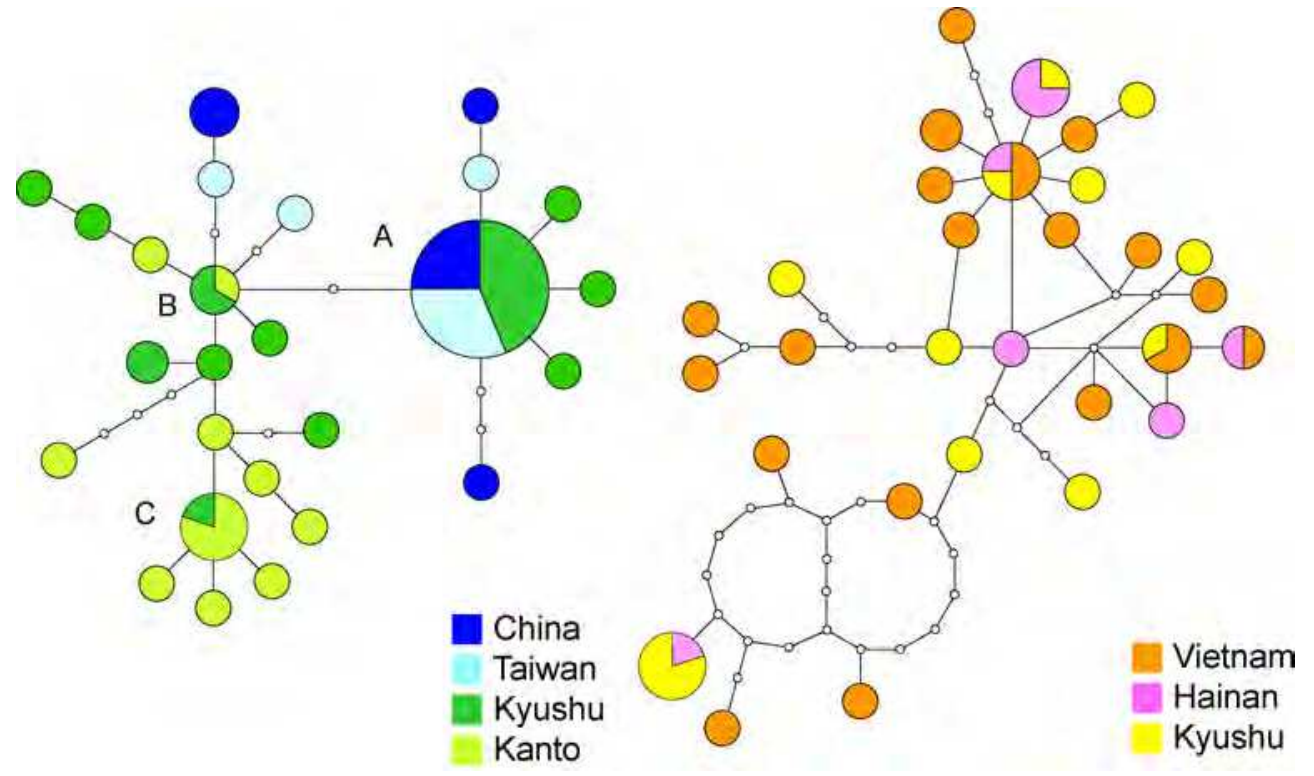

Fig. 9. Parsimonious network of two species of Haplogonatopus (left: H. oratrius, right: $H$. apicalis). Each circle indicates a different haplotype. The frequency of a geographical population is indicated by a different color.

\section{Discussion}

Host range and hibernation ability contrasts between $H$. apicalis and $H$. oratrius. However, both species have long-distance passive migration ability in association with their hosts. The 
hibernation ability of their main hosts and the host-shifting ability of dryinids at the destination locality may influence their genetic structure. According to the Palaearctic distribution of L. striatellus and their biology, H. oratrius could have been distributed widely without long-distance migration of the host. The overseas mass migration of L. striatellus demonstrated by Otuka et al. (2010) and genetic structure of $H$. oratrius suggests the presence of current gene flow among domestic populations of both species in China, Taiwan, and Kyushu. H. apicalis migrates into northern temperate regions as larvae parasitizing S. furcifera. This host probably becomes extinct each winter (Kitamura, 1987). Before the origin of rice culture in monsoonal Asia, heavy outbreaks of rice planthoppers should have occurred rarely. Gene flow within $H$. apicalis may have been accelerated by human activity. Another important dryinid species is G. fluvifermur (Esaki \& Hashimoto, 1935). It parasitizes $N$. lugens in rice paddies. The observation of insecticide resistance and virulence to resistant rice varieties implies that the East Asian population of N. lugens has different traits from the South East Asia population (Sogawa, 1992, Matsumura et al., 2008, unpublished data). During field research at Sagami-gawa River, some females of G. fluvifemur were reared from other delphacid species collected on reed bush (Phragmites australis (Cav.) Trin. ex Steud.) habitat and grasslands in Kanto, central Honshu (Mita, unpublished data). Because few individuals of $N$. lugens reach there, these dryinids might be considered to adapt to other delphacids and establish in the new locality. It is important to compare many traits of different species for further discussion on the significance of passive migration (Mita et al., in preparation).

Dryinid wasps, including apterous taxa like Haplogonatopus, can be passively transported to distant localities by their hosts. This is similar to the dispersal capability of "aerial plankton" arthropods (Richter, 1970; Bowman et al., 1978; Mound, 1983). Insect migration is often considered to be an active behavior (Drake et al., 1995); however, passive aerial dispersal of minute apterous arthropods has been reported (Washburn \& Washburn, 1984; Jung and Croft, 2001). Such species may actively launch themselves into air drafts, and are passively carried by the wind. On the other hand, the long-distance dispersal of dryinid wasps completely depends on hosts' activity. The long-distance migration of dryinid wasps together with stylops is an interesting example of passive behavior. The concept of "passive migration" is an important element in the historical biogeography of the Dryinidae. In this chapter, we reported the possibility of a local host shift by $H$. oratrius caused by the immigration of $L$. striatellus from elsewhere. So far, $H$. apicalis have not adapted to their planthopper host's destination localities. However, the expansion of the distribution caused by host dispersal is a highly probable event in certain taxa, perhaps together with host change. Consequently subsequent allopatric speciation and/or secondary contact might have occurred. The long-distance migration of their host has greatly influenced the distribution of the Dryinidae in monsoon Asia, not only in the past, but also as a progressive event.

\section{Acknowledgments}

The figure plate of the life cycle of $H$. oratrius was kindly provided by Y. Tanaka. The field research at Sagami-gawa River was conducted in collaboration with R. Watanabe and M. Oishi. We thank the following individuals for their assistance in the molecular experiment: M. Maruyama (Kyushu University Museum), F. Ryu (Kyushu University), Y. Ando, and C. Horie. We are also much indebted to the following individuals for their support on the material and assistance in field surveys: S. Yoshimatsu (National Institute of AgroEnvironmental Sciences); S. Okajima (Tokyo University of Agriculture); A. Sakai (ditto); K. 
Watanabe (Kobe University); S. Shobu (Saga Prefectural Agriculture Research Center); R. Otsu (Nagasaki Prefectural Government, Plant Protection Office); M. Kajisa (Miyazaki Plant Protection and Fertilizer Inspection); and H. Inoue (Kagoshima Prefectural Institute for Agricultural Development). This study is supported by KAKENHI 20-4137 and 22880035.

\section{References}

Asche, M. \& Wilson, M. (1990) The delphacid genus Sogatella and related groups: a revision with special reference to rice-associated species (Homoptera: Fulgoroidea). Sys. Entmol., 15, 1-42

Bowman, J., Cappuccino, N. \& Fahrig, L. (2002) Patch size and population density: the effect of immigration behavior. Conserv. Ecol., 6, 9

Chandra, G. (1980) Taxonomy and bionomics of the insect parasites of rice leafhoppers and planthoppers in the Philippines and their importance natural biological control. Philipp. Entomol., 4, 119-139

Drake, V., Gatehouse, A. \& Farrow, R. (1995) Insect migration: a holistic conceptual model, In: Insect Migration: Tracking resources through space and time, V. Drake \& A. Gatehouse (Eds.), 427-459, Cambridge University Press, UK.

Guglielmino, A. \& Olmi, M. (1997) A host-parasite catalog of world Dryinidae (Hymenoptera: Chrysidoidea). Cont. Entomol. Internat., 2(2), 165-298

Jung, C. \& Croft, B. (2001) Aerial dispersal of phytoseiid mites (Acari: Phytoseiidae): estimating falling speed and dispersal distance of adult females. Oikos, 94, 182-190

Kennedy, J. (1961) A turning point in the study of insect migration. Nature, 189, 785-791

Kifune, T. \& Maeta, Y. (1986) New host records of Elenchus japonicus (Esaki et Matsumoto, 1931) (Strepsiptera, Elenchidae) from Japan and the East China Sea. Kontyu, 54, 359-360

Kisimoto, R. (1957) Studies on the diapause in the planthoppers effect of photoperiod on the induction and completion of diapause in the fourth larval stage of the small brown planthopper, Delphacodes striatella Fallèn. Appl. Ent. Zool., 2, 128-134

Kisimoto, R. (1975) Transoceanic migration of planthopper. Chuokoronsha, Tokyo, Japan (in Japanese)

Kisimoto, R. (1983) Long-distance migration of planthoppers. Bull. Facul. Agr. Mie Univ., 67, 17-29 (in Japanese)

Kisimoto, R. \& Sogawa, K. (1995) Migration of the Brown Planthopper Nilaparvata lugens and the White-backed Planthopper Sogatella furcifera in East Asia: the role of weather and climate, In: Insect Migration: Tracking resources through space and time, V. Drake \& A. Gatehouse (Eds.), 67-90, Cambridge University Press, UK.

Kitamura, K. (1983) Comparative study on the biology of dryinid wasps in Japan (2) Relationship between temperature and the developmental velocity of Haplogonatopus atratus Esaki et Hashimoto (Hymenoptera: Dryinidae). Bull. Fac. Agr. Shimane Univ., 17, 147-151.

Kitamura, K. (1987) Seasonal changes in percentage parasitism of the parasitoids of leaf- and planthoppers in Shimane Pref. (Homoptera: Auchenorrhyncha). Bull. Fac. Agr. Shimane Univ., 21, 155-170

Kitamura, K. (1989) Comparative studies on the biology of dryinid wasps in Japan 6. Hibernation and development of Haplogonatopus atratus Esaki et Hashimoto (Hymenoptera: Dryinidae) on overwintering leaf- and planthoppers (Homoptera: Auchenorrhyncha). Jpn. J. Appl. Entomol. Zool., 33, 24-30 (in Japanese, English summary)

Kitamura, K \& Nishikata, Y (1987) A monitor-trap survey of parasitoids of the leaf- and planthoppers supposedly migrated from the mainland China (Homoptera: 
Auchenorrhyncha). Bull. Fac. Agr. Shimane Univ., 21, 171-177 (in Japanese, English summary)

Maeta, Y., Machita, Y. \& Kitamura, K. (2007) Studies on the biology of Elenchus japonicus (Esaki \& Hashimoto) (Strepsiptera, Elenchidae). Jpn. J. Entomol., 10, 33-46 (in Japanese, English summary)

Matsumoto, Y., Matsumura, M., Hoshizaki, S., Sato, Y. \& Noda, H. (2011) The strepsipteran parasite Elenchus japonicus (Strepsiptera, Elenchidae) of planthoppers consists of three genotypes. Appl. Entomol. Zool., 46, 435-442

Matsumura, M., Takeuchi, H., Satoh, M., Sanada-Morimura, S., Otuka, A., Watanabe, T. \& Thanh, DV. (2008) Species-specific insecticide resistance to imidacloprid and fipronil in the rice planthoppers Nilaparvata lugens and Sogatella furcifera in East and South-east Asia. Pest Manag. Sci., 64, 1115-1121

Mound, L. (1983) Natural and disrupted patterns of geographical distribution in Thysanoptera (Insecta). J. Biogeogr. 10, 119-133

Mun, JH., Song, YH., Heong, KL. \&, Roderick, GK. (1999) Genetic variation among Asian populations of rice planthoppers, Nilaparvata lugens and Sogatella furcifera (Hemiptera: Delphacidae): mitochondrial DNA sequences. Bull. Entomol. Res., 89, 245-253

Nishioka, T. (1980) Biological notes on Haplogonatopus atratus Esaki \& Hashimoto. Gensei, 38-39, 9-19 (in Japanese, English summery)

Olmi, M. (1999) Hymenoptera Dryinidae-Embolemidae. Fauna d'Italia, 37, Edizioni Calderini, Bologna

Olmi, M. \& Guglielmino, A. (2010) Description of Erwiniinae, new subfamily of Dryinidae from Ecuador (Hymenoptera: Chrysidoidea). Zootaxa, 2605, 56-62

Otuka, A., Watanabe, T., Suzuki, Y. \& Matsumura, M. (2005a) Estimation of the migration source for the white-backed planthopper Sogatella furcifera (Horváth) (Homoptera: Delphacidae) immigrating into Kyushu In June. Jpn. J. Appl. Entomol. Zool., 49, 187194 (in Japanese, English summary)

Otuka, A. Watanabe, T., Suzuki, Y., Matsumura, M., Furuno, A. \& Chino M. (2005b) A migration analysis of the rice planthopper Nilaparvata lugens from the Philippines to East Asia with three-dimensional computer simulations. Popul. Ecol., 47, 143-150.

Otuka, A., Matsumura, M., Sanada-Morimura, S., Takeuchi, H., Watanabe, T., Ohtsu, R. \& Inoue, H. (2010) The 2008 overseas mass migration of small brown planthopper, Laodelphax striatellus, and subsequent outbreak of rice stripe disease in western Japan. Appl. Entomol. Zool., 45, 259-266

Otuka, A., Matsumura, M., Watanabe, T. \& Dinh, T. V. (2008) A migration analysis for rice planthoppers, Sogatella furcifera (Horváth) and Nilaparvata lugens (Stål) (Homoptera: Delphacidae), emigrating from northern Vietnam from April to May. Appl. Entomol. Zool., 43, 527-534

Richter, C. (1970) Aerial dispersal in relation to habitat in eight wolf spider species (Pardosa, Araneae,Lycosidae). Oecologia 5, 200-214

Sogawa, K. (1992) A change in biotype property of brown planthopper populations immigrating into Japan and their probable source areas. Proc. Assoc. Plant. Prot. Kyushu, 38, 63-68

Sogawa, K. (1993) Source estimation of brown planthopper based upon biotype. Japan Agriculture Technology, 37, 36-40 (in Japanese)

Washburn, J. \& Washburn, L. (1984) Active aerial dispersal of minute wingless arthropods: exploitation of boundary-layer velocity gradients. Science, 223, 1088-1089 


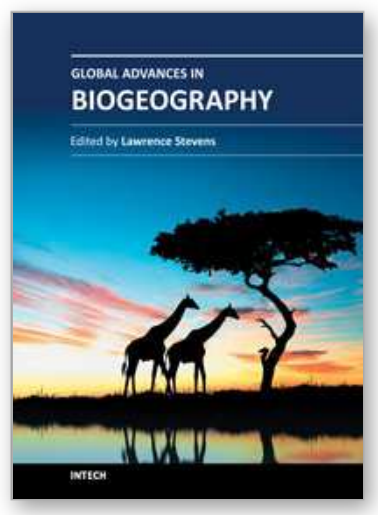

\author{
Global Advances in Biogeography \\ Edited by Dr. Lawrence Stevens
}

ISBN 978-953-51-0454-4

Hard cover, 360 pages

Publisher InTech

Published online 30, March, 2012

Published in print edition March, 2012

Global Advances in Biogeography brings together the work of more than 30 scientific authorities on biogeography from around the world. The book focuses on spatial and temporal variation of biological assemblages in relation to landscape complexity and environmental change. Global Advances embraces four themes: biogeographic theory and tests of concepts, the regional biogeography of individual taxa, the biogeography of complex landscapes, and the deep-time evolutionary biogeography of macrotaxa. In addition, the book provides a trove of new information about unusual landscapes, the natural history of a wide array of poorly known plant and animal species, and global conservation issues. This book is well illustrated with numerous maps, graphics, and photographs, and contains much new basic biogeographical information that is not available elsewhere. It will serve as an invaluable reference for professionals and members of the public interested in global biogeography, evolution, taxonomy, and conservation.

\title{
How to reference
}

In order to correctly reference this scholarly work, feel free to copy and paste the following:

Toshiharu Mita, Yukiko Matsumoto, Sachiyo Sanada-Morimura and Masaya Matsumura (2012). Passive LongDistance Migration of Apterous Dryinid Wasps Parasitizing Rice Planthoppers, Global Advances in Biogeography, Dr. Lawrence Stevens (Ed.), ISBN: 978-953-51-0454-4, InTech, Available from: http://www.intechopen.com/books/global-advances-in-biogeography/passive-long-distance-migration-ofapterous-dryinid-wasps-using-rice-planthopper

\section{INTECH}

open science | open minds

\section{InTech Europe}

University Campus STeP Ri

Slavka Krautzeka 83/A

51000 Rijeka, Croatia

Phone: +385 (51) 770447

Fax: +385 (51) 686166

www.intechopen.com

\section{InTech China}

Unit 405, Office Block, Hotel Equatorial Shanghai

No.65, Yan An Road (West), Shanghai, 200040, China

中国上海市延安西路65号上海国际贵都大饭店办公楼405单元

Phone: +86-21-62489820

Fax: +86-21-62489821 
(C) 2012 The Author(s). Licensee IntechOpen. This is an open access article distributed under the terms of the Creative Commons Attribution 3.0 License, which permits unrestricted use, distribution, and reproduction in any medium, provided the original work is properly cited. 